\title{
DOl: 10.24060/2076-3093-2017-7-2-54-61
}

\section{СВОБОДНОРАДИКАЛЬНОЕ ОКИСЛЕНИЕ И КАНЦЕРОГЕНЕЗ: ДИСКУССИОННЫЕ ВОПРОСЫ}

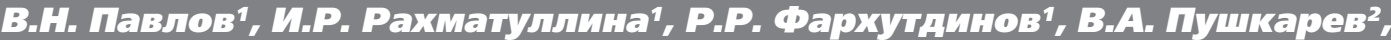 \\ К.В. Данилко1, 2.ф. Галимова', 10.ль. Баймурзина', И.В. Петрова', \\ K.C. Мочалов ${ }^{1}$
}

1 Федеральное государственное бюджетное образовательное учреждение высшего образования «Башкирский государственный медицинский университет» Министерства здравоохранения Российской Федерации, Уфа, Россия

${ }^{2}$ Государственное бюджетное учреждение здравоохранения «Республиканский клинический онкологический диспансер", Уфа, Россия

Павлов Валентин Николаевич - член-корреспондент РАН доктор медицинских наук, профессор, ректор ФГБОУ ВО БГМУ Минздрава России, Уфа, Россия, orcid.org/0000-0003-2125-4897 Рахматуллина Ирина Робинзоновна - доктор медицинских наук, профессор, проректор по научной и инновационной работе ФГБОУ ВО БГМУ Минздрава России, Уфа, Россия, orcid.org/0000 0003-0371-0385

Фархутдинов Рафагат Равильевич - доктор медицинских наук, профессор, ведущий научный сотрудник Центральной научнойисследовательской лаборатории ФГБОУ ВО БГМУ Минздрава России, Уфа, Россия, orcid.org/0000-0002-9471-6952

Пушкарев Василий Александрович - доктор медицинских наук, заведующий отделением оперативной гинекологии ГБУз «Республиканский клинический онкологический диспансер», Уфа, Россия, orcid.org/0000-0003-2620-9796

Данилко Ксения Владимировна - кандидат биологических наук, руководитель лаборатории клеточных культур, старший научный сотрудник Центральной научно-исследовательской лаборатории ФГБОУ ВО БГМУ Минздрава России, Уфа, Россия, orcid.org/00000002-4374-2923

Галимова Эльмира Фанисовна - доктор медицинских наук, ведущий научный сотрудник Центральной научно-исследовательской лаборатории ФГБОУ ВО БГМУ Минздрава России, Уфа, Россия, orcid.org/0000-0002-3351-7669

Баймурзина Юлия Львовна - кандидат биологических наук, научный сотрудник Центральной научно-исследовательской лаборатории ФГБОУ ВО БГМУ Минздрава России, Уфа, Россия, orcid org/0000-0002-5839-9793

Петрова Ирина Владимировна - младший научный сотрудник Центральной научно-исследовательской лаборатории ФГБОУ ВО БГМУ Минздрава России, Уфа, Россия, orcid.org/0000-00030669-6144

Мочалов Константин Сергеевич - кандидат биологических наук, заведующий Центральной научно-исследовательской лабораторией ФГБОУ ВО БГМУ Минздрава России, Уфа, Россия, orcid. org/0000-0002-8010-3338 450008, Россия, Башкортостан, Уфа, ул. Ленина, д.3, тел. 8 (347) 273-61-45, e-mail: cnil@bashgmu.ru

Свободные радикалы заняли прочное место среди принципов, объясняющих возникновения и развития опухолей. До сих пор нет однозначных представлений о роли этих чрезвычайно активных агентов в канцерогенезе. Экспериментальные результаты носят противоречивый, зачастую противоположный характер. Область исследования значения активности антиоксидантных систем по полученным результатам является не менее спорной. В связи с этим, актуальной проблемой является необходимость назначения антиоксидантов при онкологии. Противоопухолевые эффекты антиокси дантов ставятся под сомнение во многих работах, что выдвигает на передний план целесообразность и адекватность их назначения. Неоднозначная роль свободных радикалов в канцерогенезе обусловливает разработку терапевтических стратегий, основанных на точной модуляции окислительных процессов.

Ключевые слова: свободные радикалы, опухоли, рак, противоопухолевые пре параты, антиоксиданты. 


\title{
FREE RADICAL OXIDATION AND CARCINOGENESIS: DEBATABLE ISSUES
}

\author{
Valentin N. Pavlov', Irina R. Rakhmatullina', Rafagat R. Farkhutdinov', \\ Vasiliy A. Pushkarev², Ksenia V. Danilko', Elmira F. Galimova', Julia L. Baimurzina', \\ Irina V. Petrova', Konstantin S. Mochalov'
}

\author{
${ }^{1}$ Bashkir State Medical University, Ufa, Russian Federation \\ ${ }^{2}$ Republican Clinical Oncology Dispensary, Ufa, Russian Federation
}

Pavlov Valentin Nikolaevich - Federal State Budgetary Educational Institution of Higher Education "Bashkir State Medical University" Ministry of Health of the Russian Federation, Department of Urology, Ufa, Russian Federation, orcid.org/0000-0003-2125-4897

Rakhmatullina Irina Robinzonovna - Federal State Budgetary Educational Institution of Higher Education "Bashkir State Medical University" Ministry of Health of the Russian Federation, Ufa, Russian Federation, orcid.org/0000-0003-0371-0385

Farkhutdinov Rafagat Rarilevich - Federal State Budgetary Educational Institution of Higher Education "Bashkir State Medical University" Ministry of Health of the Russian Federation, Central Research Laboratory, Ufa, Russian Federation, orcid.org/0000-0002-9471-6952

Pushkarev Vasiliy Alexandrovich - Republican Clinical Oncology Dispensary, Ufa, Russian Federation, orcid.org/0000-0003-2620-9796

Danilko Ksenia Vladimirovna - Federal State Budgetary Educational Institution of Higher Education "Bashkir State Medical University" Ministry of Health of the Russian Federation, Central Research Laboratory, Ufa, Russian Federation, orcid.org/0000-0002-4374-2923

Galimova Elmira Fanisovna - Federal State Budgetary Educational Institution of Higher Education "Bashkir State Medical University" Ministry of Health of the Russian Federation, Central Research Laboratory, Ufa, Russian Federation, orcid.org/0000-0002-3351-7669 Baimurzina Julia Lvovna - Federal State Budgetary Educational Institution of Higher Education "Bashkir State Medical University" Ministry of Health of the Russian Federation, Central Research Laboratory, Ufa, Russian Federation, orcid.org/0000-0002-5839-9793

Petrova Irina Vladimirovna - Research assistant, Federal State Budgetary Educational Institution of Higher Education "Bashkir State Medical University" Ministry of Health of the Russian Federation, Central Research Laboratory, Ufa, Russian Federation, orcid.org/0000-0003-0669-6144

Mochalov Konstantin Sergeevich - Federal State Budgetary Educational Institution of Higher Education "Bashkir State Medical University" Ministry of Health of the Russian Federation, Central Research Laboratory, Ufa, Russian Federation, orcid.org/0000-00028010-3338, Tel.: 8 (347) 273-61-45, e-mail:cnil@bashgmu.ru

Free radicals have taken a firm place among the explanatory principles of the onset and development of tumors. Unambiguous ideas about the role of these highly active agents in carcinogenesis have not yet been obtained. The experimental results are contradictory, often the opposite. The field of study of the value of the activity of antioxidant systems based on the results obtained is no less controversial. In this regard, the urgent problem is the need to prescribe antioxidants in oncology. Antitumor effects of antioxidants are being questioned in many works, which brings to the forefront the appropriateness and adequacy of their appointment. The ambiguous role of free radicals in carcinogenesis determines the development of therapeutic strategies based on the precise modulation of oxidative processes.

Keywords: free radicals, tumors, cancer, anti-cancer drugs, antioxidants. 
Механизмы канцерогенеза и процессы трансформации нормальных клеток в опухолевые являются одной из наиболее актуальных проблем онкологии. В настоящее время в процессах пролиферации и апоптоза опухолевых клеток предполагается участие чрезвычайно активных агентов, способных взаимодействовать с органическими соединениями и инициировать цепь химических реакций, которыми являются свободные радикалы, и их разновидности, в первую очередь активные формы кислорода [1, 2, 3, 4, 5]. В последние годы вопрос о связи свободных радикалов с процессами канцерогенеза обретает новую силу и становится одним из наиболее дискуссионных. Ведутся новые исследования рака поджелудочной железы [6], рака толстой кишки [7], патогенеза и неоангиогенеза рака яичника [8], механизмов канцерогенеза в легких [9], рака шейки матки $[10,11]$ и др. Во многом это связано с тем, что, несмотря на многочисленные исследования, проведенные в этой области, до сих пор не было получено даже относительного единства в результатах. Экспериментальные данные носят противоречивый характер.

\section{Оксидативный стресс и канцерогенез}

В работах по проблеме окислительного свободнорадикального метаболизма главным образом изучаются процессы избыточного образования гиперпродукции свободных радикалов в опухолевых клетках $[12,13,14]$. Гиперпродукция свободных радикалов, как известно, составляет основу феномена оксидативного стресса, который выступает фактором молекулярной и тканевой деструкций и является патогенетическим звеном, опосредствующим развитие ряда заболеваний [15, 16, 17, 18, 19]. Lushchak V.I. отмечает, что, несмотря на более чем тридцатилетнее применение понятия «окислительный стресс», общепринятой классификации для этого феномена выработано не было и предлагает разделять окислительный стресс на категории в зависимости от его интенсивности [20]. Сложность экспериментального исследования окислительного стресса заключается в том, что ни один биомаркер не может в полной мере служить его оценкой [21]. Для оценки окислительного стресса необходим набор различных показателей и учет множества переменных, имеющих отношение к про- и антиоксидантным воздействиям [22,23]

Опухолевые клетки постоянно подвергаются воздействию активных форм кислорода, вызывающих окислительный стресс. Цитотоксические эффекты лучевой терапии во многом обусловлены развитием окислительного стресса. При этом окислительный стресс является причиной и следствием злокачественной трансформации [24].

\section{Двойственная роль свободных радикалов в канцерогенезе}

Мнения исследователей и клиницистов разделяются и часто носят противоположный характер как относительно роли свободных радикалов при раке, так и связанных с ними механизмов защиты
- ферментных клеточных систем, а также применения антиоксидантов при злокачественных новообразованиях.

Активные формы кислорода играют инициативную роль в развитии и прогрессировании опухолей путем индукции мутаций ДНК, нестабильности генома и протонкогенной сигнализации. С другой стороны, высокие уровни свободных радикалов могут быть токсичными для раковых клеток и потенциально вызывать их гибель [25]. Противоположные сведения о способности свободных радикалов либо вызывать, либо ингибировать образование опухолей, очевидно, связаны с изменением функции радикалов в зависимости от конкретных условий. Такими условиями могут быть: интенсивность свободнорадикальных процессов, их локализация и динамика. К примеру, существуют данные о дозозависимом характере влияния свободных радикалов. Было показано, что высокие концентрации свободных радикалов ингибируют пролиферацию, а низкие, наоборот, проявляют ростстимулирующую активность по отношению к опухолевым клеткам [26]. Относительно высокая концентрация H2O2 способствует росту и пролиферации клеток рака молочной железы. Однако чрезмерное внутриклеточное содержание $\mathrm{H} 2 \mathrm{O} 2$, наоборот, приводит к гибели клеток рака молочной железы [27]. Отмечается подавление роста опухолевых клеточных линий в условиях острого оксидативного стресса. В условиях же хронического стресса наблюдаются противоположные процессы: усиливается рост клеток и повышается их выживаемость [28]. Если при остром окислительном стрессе происходит повреждение компонентов клетки, то при хроническом окислительном стрессе стимуляция канцерогенеза может происходить путем изменения экспрессии генов, связанных с раком, и вызывающих мутацию и трансформацию [29].

\section{Химиопрепараты и антиоксиданты в терапии онкологии}

Разные экспериментальные данные обусловливают и разные терапевтические подходы. Двойственная роль свободных радикалов в канцерогенезе является основой для дискуссии о противоположных стратегиях регуляции окислительных процессов [27]. В первую очередь это относится к применению противоопухолевых препаратов. На фоне противоопухолевой терапии образуется повышенное количество свободных радикалов, инактивируются ферментные антиоксидантные системы, что приводит к интоксикации, повреждению клеток, тканей и органов [30]. При этом побочное токсическое действие противоопухолевых препаратов напрямую объясняется их прооксидантными свойствами [31]. В этой связи актуальным вопросом является нейтрализация окислительного стресса при действии противоопухолевых препаратов антиоксидантами (модификация химиотерапии антиоксидантотерапией). Ведутся экспериментальные и клинические исследования эффективности назначения химиопрепаратов совместно с антиоксидантами 
различной химической основы [30,32,33,34,35]. Улучшение переносимости химиотерапии с антиоксидантами было отмечено в ряде работ [36, 37].

На клеточной линии гепатоцеллюлярной карциномы НерG2 было показано, что обработка перекисью водорода приводит к окислительному стрессу и снижению антиоксидантной активности. НерG2клетки, обработанные Н2O2, обладали более высокой способностью к миграции и инвазивностью. Совместное применение антиоксидантов - ацетата токоферола (TA) и S-аденозилметионина (SAM) эффективно ослабляло экспрессию фактора Nrf2 и 8-гидроксидеоксигуанозина (8-OHdG) в HepG2клетках. Таким образом, инвазивность и миграция этих клеток существенно снижается в присутствии антиоксидантов [38].

В современных исследованиях раскрывается роль антиоксидантов в предотвращении и ингибировании рака полости рта, а также его профилактики [39]. Рассматривается применение нутрицевтиков для ликвидации раковых клеток [40]. В последнее время, антиоксидантная терапия и диетические добавки антиоксидантов вызывают значительный интерес в лечении рака шейки матки [41].

Другая точка зрения основывается на том, что назначение антиоксидантов ингибирует противоопухолевый эффект химиопрепаратов, а сами антиоксиданты в этом случае способны лишь провоцировать рак $[42,43]$. Эта позиция предполагает, что при раковых заболеваниях происходит смещение нормального окислительного состояния в сторону преобладания в опухолевых клетках антиоксидантов. Антиоксиданты могут не оказывать положительного противоопухолевого эффекта. В частности, витаминные и антиоксидантные добавки не вызывали профилактического эффекта при раке мочевого пузыря [44]. Более того, антиоксиданты не всегда безопасны для использования: их чрезмерное потребление может приводить к серьезным проблемам со здоровьем [45]. При блокировании антиоксидантами окислительного стресса упраздняется механизм апоптоза опухолевых клеток, реализуемый через образование свободных радикалов. Поэтому защита здоровых тканей антиоксидантами в данном случае является препятствием для уничтожения раковых тканей. В этой связи нобелевским лауреатом Дж. Уотсоном, отстаивающим данную точку зрения, даже был поднят вопрос о разработке новых препаратов обладающих антиантиоксидантной активностью [46].

Высокие уровни активных форм кислорода способны предупреждать развитие опухолей. Этот факт делает прооксидантную терапию рака перспективной областью исследования [25]. Противоречивая роль активных форм кислорода предполагает разработку лечебных методов, направленных на модуляцию уровней окислительных процессов $[47,48]$. В этом направлении предлагаются различные терапевтические стратегии. В частности, путем доставки цитотоксических активных форм кислорода непосредственно к опухолям, была разработана так называемая «окислительная терапия», как альтернатива ингибированию антиоксидантных систем [49]. Некоторые противоопухолевые препараты, такие как паклитаксел, способны атаковать раковые клетки за счет генерации активных форм кислорода или мешать их выработке. Другие противораковые агенты, в частности пайперлонгумин (piperlongumine), связываются с активными участками ключевых клеточных антиоксидантов, включая глутатион-S-трансферазу и карбонил-редуктазу [50].

\section{Значение активности ферментов антиокси- дантной системы в канцерогенезе}

Спорным вопросом также является значение активности ферментных антиокислительных систем клеток при раке. Согласно одной из точек зрения, при перерождении нормальных клеток в раковые запускаются интенсивные метаболические пути пролиферации. Эти же пути приводят к избыточному образованию свободных радикалов, обладающих цитотоксичностью. Клеточный оксидативный стресс инициирует окисление белков, липидов и ДНК и таким образом препятствует опухолегенезу и выживанию клеток. В качестве ответа на усиление оксидации в опухолевых клетках начинают усиленно функционировать ферментные антиоксидантные системы, в частности глутатион-пероксидаза, для защиты клеток [51]. В эксперименте на мышах с блокированным печеночным липогенезом (посредством нокаута генов ацетил-СоА-карбоксилазы) введение диэтилнитрозамина приводило к развитию гепатоклеточных карцином. Блокирование липогенеза мышей характеризовалось двукратным увеличением опухоли. При этом оказалось, что антиоксидантный метаболизм гепатоцитов значительно возрастал, включая NADPH и восстановленный глутатион, что, очевидно, и повышало выживаемость клеток [52]. Имеются также данные о высоких уровнях активности ферментных систем каталазы, обеспечивающих устойчивость опухолевых клеток к окислению. Это может быть использовано в терапии рака путем ингибирования гомеостаза глутатиона [2]. Но вместе с тем, показано, что клетки и с низкой активностью каталазы могут быть более устойчивыми к токсическим прооксидантам. Эти опухолевые клетки более устойчивы по сравнению с клетками с высокой активностью фермента. Таким образом, не было установлено прямой корреляции между уровнем активности каталазы и чувствительностью к прооксидантам [53]. При раке молочной железы характерны усиленная экспрессия супероксиддисмутазы (SOD) и одновременно пониженная активность каталазы с большой резистентностью к перекиси водорода [54]. В исследованиях [55], наоборот, наблюдалась более высокая активность каталазы в эпителиальных клетках MDA-MB-231 рака молочной железы.

Дефекты в антиоксидантных ферментных системах сами по себе являются предпосылкой для онкогенеза. В частности, дисбаланс окислительных ферментов приводит к перепроизводству активных форм кислорода, повреждению ДНК в клетках шейки матки. При этом клетки становятся более уязви- 
мыми для вируса папилломы человека и соответственно для развития цервикального рака [41].

\section{Основные тенденции экспериментальных исследований свободнорадикальных процес- сов в онкогенезе}

В настоящее время наиболее перспективные, адекватные и точные методы исследования in vitro процессов канцерогенеза основаны на использовании культур опухолевых клеток. При этом опухолевая клетка выступает непосредственным объектом исследования, что позволяет получать высокоспецифичные и достоверные результаты. На культурах клеток разрабатываются методы индивидуального подбора противоопухолевых препаратов in vitro для конкретных пациентов в рамках персонализированного подхода к медицине [56]. Большое количество современных работ по исследованию роли оксидативного стресса в генезе опухолей ведутся именно на моделях клеточных культур [57]. Изучение механизмов канцерогенеза, оценка противоопухолевых препаратов в существующих исследованиях производятся в основном на изолированных клеточных линиях. Исследование на клеточных линиях имеет как преимущества, так и недостатки.

В большинстве проводимых в настоящее время исследований в опухолевых клетках индуцируются процессы гиперпродукции свободных радикалов, что приводит к развитию оксидативного стресса и процессам апоптоза клеток. Базальный же уровень активности свободнорадикальных процессов, как правило, не выступает отдельным предметом исследований

В существующих работах исследования сосредоточены в основном на определении активированных форм кислорода. При этом определяется внутриклеточное накопление активных форм кислорода и, кроме того, исследуется состояние антиоксидантных систем клеток. Однако нарушение окислительного метаболизма не ограничивается процессами дисбаланса активных форм кислорода; оно также приводит к неконтролируемому образованию продуктов пероксидации, в первую очередь липидов [58].

Направления исследований в области окислительных процессов и рака сосредоточены на определении внутриклеточного состояния свободнорадикальных процессов. В то же время большое значение имеет не только состояние внутриклеточных процессов, но и состояние свободнорадикальных процессов окружения - в среде культивирования клеток.

\section{Возможные подходы в дальнейших исследо- ваниях роли свободных радикалов в канце- poremeze}

Дискуссионные вопросы, рассмотренные в статье, являются основанием для проведения дальнейших исследований связи свободнорадикальных процессов с развитием опухолей на клеточных моделях. Эти исследования должны носить комплексный характер. Для реализации комплексного подхода в эксперименте необходимо проанализировать и учесть обстоятельства, вытекающие из методологии большинства проводимых в данной области исследований.

В этом отношении перспективным представляется исследование, проводимое как на клеточных линиях, так и на первичных культурах клеток, содержащих помимо опухолевых клеток и другие клеточные элементы. Это позволит моделировать естественные условия реализации окислительных процессов, происходящих в опухолях. Кроме того, необходима комплексная оценка всей системы свободно-радикального метаболизма: не только генерации активных форм кислорода - начального звена свободнорадикальных процессов, но и реакций переокисления липидов. Вместе с тем должны оцениваться не только процессы свободнорадикального окисления в форме окислительного стресса, но и исходный уровень активации опухолевых клеток. Также большое значение в планируемых исследованиях имеет не только оценка состояния внутриклеточных процессов (внутриклеточного накопления активных форм кислорода), но и состояния свободнорадикальных процессов окружения - в среде культивирования клеток.

\section{ЗАКЛЮЧЕНИЕ}

Очевидно, что парадоксальная природа свободных радикалов выполнять как полезные физиологические функции, так и приносить вред находит отражение и в процессах канцерогенеза. Вопрос о связи радикалов и онкологических заболеваний в настоящее время далеко не исчерпан. Только дальнейший экспериментальный анализ позволит внести уточнения и конкретизацию, сформировать систематизированные представления по данному вопросу. Главным здесь представляется выяснение условий, при которых роль радикалов может изменяться на противоположную (из противоопухолевой в опухолеиндуцирующую и наоборот).

\section{СПИСОК ЛИТЕРАТУРЫИREFERENCES}

1. Шапошников $A B$, Рядинская ЛА. Канцерогенез и оксидативный стресс. Кубанский научный медицинский вестник. 2010;(3-4):211-215. [Shaposhnikov AV, Rjadinskaja LA. Cancerogenesis and oxidative stress. Kuban Scientific Medical Bulletin. 2010;(3-4):211-15 (in Russ.)].

2. Schumacker PT. Reactive oxygen species in cancer: a dance with the devil. Cancer Cell. 2015; 27(2):156-7. DOI: 10.1016/j.ccell.2015.01.007.

3. Martinez-Outschoorn UE, Balliet RM, Rivadeneira DB, Chiavarina B, Pavlides S, Wang C, et al. Oxidative stress in cancer associated fibroblasts drives tumor-stroma co-evolution: a new paradigm for understanding tumor metabolism, the field effect and genomic instability in cancer cells. Cell Cycle. 2010;9(16):3256-76. DOI: 10.4161/cc.9.16.12553.

4. Shrihari TG. Dual role of inflammatory mediators in cancer. Ecancermedicalscience. 2017;11:721. DOI: 10.3332/ecancer.2017.721. 
5. Katakwar P, Metgud R, Naik S, Mittal R. Oxidative stress marker in oral cancer: a review. J Cancer Res Ther. 2016;12(2):438-46. DOI:10.4103/09731482.151935.

6. Martinez-Useros J, Li W, Cabeza-Morales M, Garcia-Foncillas J. Oxidative stress: a new target for pancreatic cancer prognosis and treatment. J Clin Med. 2017;6(3):29. DOI:10.3390/jcm6030029.

7. Juhasz A, Markel S, Gaur S, Liu H, Lu J, Jiang $G$, et al. NADPH oxidase 1 supports proliferation of colon cancer cells by modulating reactive oxygen species-dependent signal transduction. J Biol Chem. 2017;292(19): 7866-87. DOI: 10.1074/jbc.M116.768283.

8. Saed GM, Diamond MP, Fletcher NM. Updates of the role of oxidative stress in the pathogenesis of ovarian cancer. Gynecol Oncol. 2017 Feb 23. Epub ahead of print. DOI: 10.1016/j.ygyno.2017.02.033.

9. Valavanidis A, Vlachogianni T, Fiotakis K, Loridas S. Pulmonary oxidative stress, inflammation and cancer: respirable particulate matter, fibrous dusts and ozone as major causes of lung carcinogenesis through reactive oxygen species mechanisms. Int J Environ Res Publ. Health. 2013;10(9):3886-907. DOl:10.3390/ ijerph10093886.

10. Looi ML, Mohd Dali AZ, Md Ali SA, Wan Ngah WZ, Mohd Yusof YA. Oxidative damage and antioxidant status in patients with cervical intraepithelial neoplasia and carcinoma of the cervix. Eur J Cancer Prev. 2008;17(6):555-60. DOI: 10.1097/ CEJ.0b013e328305a10b.

11. Marinescu S, Anghel R, Gruia MI, Beuran $M$. Involvement of reactive oxygen species in the mechanisms associated with cervical cancer specific treatment. Chirurgia (Bucur). 2014;109(6):806-11. PMID: 25560505

12. Емельянов МО, Ким ЮА, Корыстова АФ, Кублик ЛН, Шапошникова ВВ, Корыстов ЮН. Быстрое подавление множественной лекарственной устойчивости лейкозных клеток окислительным стрессом. Биологические мембраны: Журнал мембранной и клеточной биологии. 2010;27(3):244251. [EmelYanov MO, Korystova AF, Kublik LN, Shaposhnikova VV, Korystov YuN, Kim YuA. Rapid suppression of multidrug resistance of leukemic cells by oxidative stress. Biochemistry (Moscow) Supplement. Series A: Membrane and Cell Biology. 2010;4(2):212219]. DOI: $10.1134 /$ S1990747810020133.

13. Рязанцева НВ, Степовая ЕА, Коновалова ЕВ, Носарева ОЛ, Наумова АИ, Орлов ДС, и др. Моделирование окислительного стресса в лимфоцитах крови in vitro для изучения апоптоза опухолевых клеток линии JURKAT. Казанский медицинский журнал. 2013;94(5):736-740. [Ryazantseva NV, Stepovaya EA, Konovalova EV, Nosareva OL, Naumova AI, Orlov DS, et al. Oxidative stress modeling in the blood lymphocytes in vitro to examine the jurkat line tumor cells apoptosis. Kazan Medical Journal. 2013;94(5):736-740 (in Russ.)].

14. Шахристова ЕВ, Рязанцева НВ, Степовая ЕА, Носарева ОЛ. Индукция пероксидом водорода окислительного стресса in vitro в эпителиальных клетках молочной железы для изучения апоптоза опухолевых клеток линии MCF-7. Сибирский научный медицинский журнал. 2015;35(2):510. [Shakhristova EV, Ryazantseva NV, Stepovaya EA, Nosareva OL. Induction of oxidative stress by hydrogen peroxide in vitro in breast epithelial cells for studying MCF-7 tumor cell line apoptosis. Siberian Scientific Medical Journal. 2015;35(2):5-10 (in Russ.)]

15. Владимиров ЮА, Проскурнина ЕВ. Свободные радикалы и клеточная хемилюминесценция. Успехи биологической химии. 2009;49:341-388.

16. Lyamzaev KG, Pustovidko AV, Simonyan RA, Rokitskaya TI, Domnina LV, Ivanova OYu, et al. Novel mitochondria-targeted antioxidants: plastoquinone conjugated with cationic plant alkaloids berberine and palmatine. Pharm Res. 2011;28(11):2883-2895. DOI: 10.1007/s11095-011-0504-8.

17. Фархутдинов РР, Галимов ШН, Галимова ЭФ. Свободнорадикальное окисление в норме и патологии. Практикующий врач сегодня. 2010;(2):5461. [Farkhutdinov RR, Galimov ShN, Galimova EF. Free radical oxidation in health and disease. Practitioner Doctor Today. 2010; (2):54-61 (in Russ.)].

18. BarreraG.Oxidativestressandlipid peroxidation products in cancer progression and therapy. ISRN Oncol. 2012;2012:21. DOI: 10.5402/2012/137289.

19. Bhat AH, Dar KB, Anees S, Zargar MA, Masood $A$, Sofi $M A$, et al. Oxidative stress, mitochondrial dysfunction and neurodegenerative diseases; a mechanistic insight. Biomed Pharmacother. 2015;74:101-10. DOI: 10.1016/j.biopha.2015.07.025.

20. Lushchak VI. Free radicals, reactive oxygen species, oxidative stress and its classification. Chem Biol Interact. 2014;224:164-75. DOI: 10.1016/j. cbi.2014.10.016.

21. Eldridge RC, Flanders WD, Bostick RM, Fedirko V, Gross M, Thyagarajan B, et al. Using multiple biomarkers and determinants to obtain a better measurement of oxidative stress: a latent variable structural equation model approach. Biomarkers. 2017 Mar 29:1-8. Epub ahead of prin. DOI: 10.1080/1354750X.2017.1306752

22. Павлов ВН, Галимова ЭФ, Катаев ВА, Фархутдинов РР, Мочалов КС, Баймурзина ЮЛ, и др. Сравнительный анализ антиоксидантных эффектов Коэнзима Q и L-карнитина у мужчин с идиопатической патоспермией. Медицинский вестник Башкортостана. 2013;8(6):161-163. [Pavlov VN, Galimova EF, Kataev VA, Farkhutdinov RR, Mochalov KS, Baimurzina JuL, et al. The comparative analysis of coenzyme $Q$ and $\mathrm{L}$-carnitine antioxidant effects in men with idiopathic pathospermia. Bashkortostan Medical Journal. 2013;8(6):161-163 (in Russ.)]

23. Павлов ВН, Галимова ЭФ, Мочалов КС, Петрова ИВ, Баймурзина ЮЛ, Зарипова РМ, и др. Оценка влияния L-карнитина на репродуктивную функцию мужчин с идиопатической патоспермией. Медицинский вестник Башкортостана. 2012;7(4):3640. [Pavlov VN, Galimova EF, Mochalov KS, Petrova IV, Baymurzina YuL, Zaripova RM, et al. Estimating I-carnitine influence on reproductive function in men with idiopathic patospermia. Bashkortostan Medical Journal. 2012;7(4):36-40 (in Russ.)]. 
24. Serbanescu GL, Gruia MI, Bara M, Anghel RM. The evaluation of the oxidative stress for patients receiving neoadjuvant chemoradiotherapy for locally advanced rectal cancer. J Med Life. 2017;10(1):99-103. PMID: 28255388

25. Glasauer A, Chandel NS. Targeting antioxidants for cancer therapy. Biochem Pharmacol. 2014;92(1):90101. DOI: 10.1016/j.bcp.2014.07.017.

26. Кондакова ИВ, Какурина ГВ, Смирнова ЛП, Борунов ЕВ. Регуляция пролиферации и апоптоза опухолевых клеток свободными радикалами. Сибирский онкологический журнал. 2005;(1):58-61. [Kondakova IV, Kakurina GV, Smirnova LP, Borunov EV. Regulation of tumor cell proliferation and apoptosis by free radicals. Siberian Journal of Oncology. 2005; (1):58-61 (in Russ.)]

27. Wang J, Yi J. Cancer cell killing via ROS: to increase or decrease, that is the question. Cancer Biol Ther. 2008;7(12):1875-84. PMID: 18981733.

28. Prathap Kumar S Mahalingaiah, Kamaleshwar P Singh. Chronic oxidative stress increases growth and tumorigenic potential of MCF-7 breast cancer cells. PLoS One. 2014;9(4):e93799. DOl.org/10.1371/journal. pone.0087371.

29. Kruk J, Aboul-Enein HY. Reactive oxygen and nitrogen species in carcinogenesis: Implications of oxidative stress on the progression and development of several cancer types. Mini Rev Med Chem. 2017 Feb 28. Epub ahead of print. DOI: 10.2174/13895575176661 70228115324.

30. Зорькина AB, Скопин ПИ. Модификация противоопухолевой химиотерапии антиоксидантными препаратами в эксперименте. Сибирский онкологический журнал. 2011;1(43):34-39. [Zorkina AV, Skopin PI. Modification of antitumor therapy with antioxidant drugs in experimental studies. Siberian Journal of Oncology. 2011;1(43):34-39 (in Russ.)].

31. Лалетин ВС, Колесниченко ЛС. Липоевая кислота как потенциальный прооксидант. Сибирский медицинский журнал (Иркутск). 2010;92(1):7274. [Laletin VS, Kolesnichenko LS. Lipoic acid as a potential prooxidant. Siberian Medical Journal (Irkutsk). 2010;92(1):72-74 (in Russ.)].

32. Микуляк НИ, Миннигалеева СД, Магдеев РP, Кинзирский АС, Микуляк АИ, Соломанина ОО. Оценка влияния карубицина при раздельном и сочетанном применении с пробуколом, мексидолом, -токоферолом на рост первичного опухолевого узла и метастазирование карциномы легких Льюис. Фундаментальные исследования. 2014;7-4:753758. [Mikuleak NI, Minnigaleeva SD, Magdeyev RR, Kinzirsky AS, Mikulyak AL, Solomanina OO. Valuation of the impact of separate and combined use of carubicinum with probucol, mexidol and -tocopherol on the growth of primary tumor and metastasis of lewis lung carcinoma. Fundamental Research. 2014;74:753-758 (in Russ.)]

33. Потапова АА, Доркина ЕГ, Сергеева ЕО, Саджая ЛА. Влияние сухого экстракта из корней Шлемника Байкальского (scutellaria baicalensis georgi) на развитие окислительного стресса, вызванного циклофосфаном. Современные проблемы науки и образования. 2013;6:667. [Potapova AA, Dorkina EG, Sergeeva EO, Sadzhaya LA. Effects of dry root extract scutellaria baicalensis georgi on development oxidative stress induced by cyclophosphamide. Modern Problems of Science and Education. 2013;6:667 (in Russ.)].

34. Скопин ПИ, Скопина ЮА, Евстифеев СВ, Сухова ЛА, Кулаев МТ, Куслина АВ. Антиоксиданты на основе 3-оксипиридинов повышают эффективность противоопухолевых препаратов. Современные проблемы науки и образования. 2016;2:75. [Skopin PI, Skopina YuA, Evstifeev SV, Sukhova LA, Kulaev MT, Kuslina AV. 3-hydroxypyridine based antioxidants increase efficiency of anticancer drugs. Modern Problems of Science and Education. 2016;2:75 (in Russ.)].

35. Tekiner-Gulbas B, Westwell AD, Suzen S. Oxidative stress in carcinogenesis: new synthetic compounds with dual effects upon free radicals and cancer. Curr Med Chem. 2013;20(36):4451-9. PMID: 23834180.

36. Block KI, Koch AC, Mead MN, Tothy PK, Newman RA, Gyllenhaal C. Impact of antioxidant supplementation on chemotherapeutic toxicity: a systematic review of the evidence from randomized controlled trials. Int J Cancer. 2008;123(6):1227-39. DOI: 10.1002 /ijc. 23754

37. Simone $C B$, Simone $N L$, Simone $V$, Simone CB. Antioxidants and other nutrients do not interfere with chemotherapy or radiation therapy and can increase kill and increase survival, part 1. Altern. Ther. Health Med. 2007;13:22-28. PMID: 17283738.

38. Ma-OnC, SanpavatA, WhongsiriP, Suwannasin S, Hirankarn N, Tangkijvanich $P$. Oxidative stress indicated by elevated expression of $\mathrm{Nrf2}$ and 8-OHdG promotes hepatocellular carcinoma progression. Med Oncol. 2017;34(4):57. DOI: 10.1007/s12032-017-09145 .

39. Choudhari SK, Chaudhary M, Gadbail AR, Sharma A, Tekade S. Oxidative and antioxidative mechanisms in oral cancer and precancer: a review. Oral Oncol. 2014;50(1):10-8. DOI: 10.1016/j. oraloncology.2013.09.011.

40. Prasad S, Gupta SC, Tyagi AK. Reactive oxygen species (ROS) and cancer: role of antioxidative nutraceuticals. Cancer Lett. 2017;387:95-105. DOl: 10.1016/j.canlet.2016.03.042

41. Jiang B, Xiao S, Khan MA, Xue M. Defective antioxidant systems in cervical cancer. Tumour Biol. 2013;34(4):2003-9. DOl: 10.1007/s13277-013-0804-1.

42. Le Gal K, Ibrahim MX, Wiel C, Sayin VI, Akula MK, Karlsson C, et al. Antioxidants can increase melanoma metastasis in mice. Sci Transl Med. 2015;7(308):308. DOI: 10.1126/scitranslmed.aad3740.

43. Sayin VI, Ibrahim MX, Larsson E, Nilsson JA, Lindahl P, Bergo MO. Antioxidants accelerate lung cancer progression in mice. Sci Transl Med. 2014;6:221. DOI: 10.1126 /scitranslmed.3007653.

44. Park SJ, Myung SK, Lee Y, Lee YJ. Effects of vitamin and antioxidant supplements in prevention of bladder cancer: a meta-analysis of randomized controlled trials. J Korean Med Sci. 2017;32(4):628-35. DOI: 10.3346/jkms.2017.32.4.628. 
45. Tong L, Chuang CC, Wu S, Zuo L. Reactive oxygen species in redox cancer therapy. Cancer Lett. 2015;367(1):18-25. DOl: 10.1016/j.canlet.2015.07.008.

46. Watson J. Oxidants, antioxidants and the current incurability of metastatic cancers. Open Biol. 2013;3(1):120144. DOl:10.1098/rsob.120144.

47. Gorrini C, Harris IS, Mak TW. Modulation of oxidative stress as an anticancer strategy. Nat Rev Drug Discov. 2013;12(12):931-47. DOI: 10.1038/nrd4002.

48. Smith DG, Magwere T, Burchill SA. Oxidative stress and therapeutic opportunities: focus on the Ewing's sarcoma family of tumors. Expert Rev Anticancer Ther. 2011;11(2):229-49. DOI: 10.1586/ era.10.224.

49. Fang J, Seki T, Maeda H. Therapeutic strategies by modulating oxygen stress in cancer and inflammation. Adv Drug Deliv Rev. 2009;61(4):290302. DOI: $10.1016 / j . a d d r .2009 .02 .005$

50. Saeidnia S, Abdollahi M. Antioxidants: friends or foe in prevention or treatment of cancer: the debate of the century. Toxicol Appl Pharmacol. 2013;271(1):4963. DOI: 10.1016/j.taap.2013.05.004.

51. Калинина ЕВ, Чернов НН, Саприн АН. Участие тио-, перокси- и глутаредоксинов в клеточных редоксзависимых процессах. Успехи биологической химии. 2008;48:319-358. [Kalinina EV, Saprin AN, Chernov NN. Involvement of thio-, peroxi-, and glutaredoxins in cellular redox-dependent processes. Biochemistry (Moscow). 2008;73(13):1493-1510]. DOI: 10.1134/S0006297908130099.

52. Nelson ME, Lahiri S, Chow JD, Byrne FL, Hargett $\mathrm{SR}$, Breen DS, et al. Inhibition of hepatic lipogenesis enhances liver tumorigenesis by increasing antioxidant defence and promoting cell survival. Nat Commun. 2017;8:14689. DOI: 10.1038/ncomms14689.

53. Сидорова ТА, Вагида МС, Калия ОЛ, Герасимова ГК. Роль каталазы в защите опухолевых клеток от окислительного стресса, индуцированного бинарной каталитической системой «терафтал + аскорбиновая кислота». Клиническая онкогематология. 2014;7(3):282-289. [Sidorova TA, Vagida MS, Kaliya OL, Gerasimova GK. Role of catalase in protection of cancer cells from oxidative stress induced by binary catalytic system "teraphtal + ascorbic acid". Clin Oncohematol. 2014;7(3):282-289 (in Russ.)].

54. Wang L, Luo X, Li C, Huang Y, Xu P, LloydDavies $L H$, et al. Triethylenetetramine synergizes with pharmacologic ascorbic acid in hydrogen peroxide mediated selective toxicity to breast cancer cell. Oxid Med Cell Longev. 2017;2017:3481710. DOI: 10.1155/2017/3481710.

55. Hecht F, Cazarin JM, Lima CE, Faria CC, Leit o $A A$, Ferreira AC, et al. Redox homeostasis of breast cancer lineages contributes to differential cell death response to exogenous hydrogen peroxide. Life Sci. 2016;158:7-13. DOI: 10.1016/j.Ifs.2016.06.016.

56. Чернов АН, Яцков НН, Скакун ВВ. Исследование чувствительности клеток интракраниальных неоплазий кхимиопрепаратам. Российский журнал детской гематологии и онкологии. 2015;2(4):51-57. [Chernov AN, Yatskov NN, Skakun VV. Research of the intracranial neoplasia cell sensitivity to chemotherapy drugs. Rus J Child Hematol Oncol. 2015;2(4):51-57 (in Russ.)].

57. Shah MH, Liu GS, Thompson EW, Dusting GJ, Peshavariya HM. Differential effects of superoxide dismutase and superoxide dismutase/catalase mimetics on human breast cancer cells. Breast Cancer Res Treat. 2015;150(3):523-34. DOI: 10.1007/s10549015-3329-z.

58. Герасименко МН, Зуков РА, Титова НМ, Дыхно ЮА, Модестов АА, Попов ДВ. Антиоксидантная система и маркеры окислительного стресса при раке почки. Сибирский онкологический журнал. 2012;5(53):39-43. [Gerasimenko MN, Zukov RA, Titova NM, Dvkhno YuA, Modestov AA, Popov DV. Antioxidant system and markers of oxidative stress in renal cell cancer. Siberian J Oncol. 2012;5(53):39-43 (in Russ.)]. 